\title{
A Qualitative Study on Industry 4.0 Competitiveness in Turkey Using Porter Diamond Model
}

\author{
Gizem ErboziD \\ Szent Istvan University (Hungary) \\ gizemerboz.ge@gmail.com
}

Received: April 2019

Accepted: March 2020

\begin{abstract}
:
Purpose: Industry 4.0 offers a new network approach by using advanced Information and Communication Technologies (ICT) for manufacturing industries in particular. Thus, this paper analyzes the understandings of the heavy manufacturing industry in Turkey in regards to the concept of Industry 4.0 as well as its significance on the nation's competitiveness. In addition, the study applies Porter's Diamond Model as a framework in order to provide a dynamic view about the competitive factors in the development of Industry 4.0.

Design/methodology/approach: The results of fourteen semi structured interviews are examined in the framework, and common understandings are compared with the existing literature.

Findings: The analysis indicates that the heavy manufacturing companies are aware of the topic of Industry 4.0 in general in terms of its definition, its future aspects, and its possible benefits and challenges. It has been observed that factor conditions (labor and capital) are the most important aspects which affect the development of Industry 4.0 competitiveness in Turkey. Although the country is still in the initial stage in its Industry 4.0 competitiveness, the effects of the government and some chances might increase its competitive position in the future.

Originality/value: Regarding the different research on Industry 4.0, this paper gives an insight in the developmental path of Industry 4.0 in terms of its competitiveness especially for developing countries. There is still a lack of empirical research on nations' competitiveness about Industry 4.0; therefore, this paper deepens the concept for further research and examines some action plans about it.
\end{abstract}

Keywords: industry 4.0, technology, diamond model, competitiveness, manufacturing companies

\section{To cite this article:}

Erboz, G. (2020). A Qualitative Study on Industry 4.0 Competitiveness in Turkey Using Porter Diamond Model. Journal of Industrial Engineering and Management, 13(2), 266-282. https://doi.org/10.3926/jiem.2915

\section{Introduction}

The concept of Industry 4.0 is a network approach which applies the principles of Cyber Physical Systems (CPS) and internet technologies. By using smart systems and well proven Internet standards, Industry 4.0 approaches to standardize these technologies in order to stimulate value streams in the manufacturing industry (Kolberg \& 
Zühlke, 2015; Sanders, Elangeswaran \& Wulfsberg, 2016). Even today, we can observe that many shifts occur in the transition of work from the physical to the virtual world. Within the effects of advanced digitalization in factories, internet technologies and smart components will result in remarkable changes in industrial production, both increasing efficient manufacturing systems and the scenarios where products can control their own manufacturing process via real time communication (Lasi, Fettke, Kemper, Feld \& Hoffmann, 2014; Kagermann, 2015). The vision of Industry 4.0 could be seen as using complex digital systems in order to create linkage within a production process, including a customer's order and upstream and downstream activities. By doing this, the smart activities lead to achieving economies of scale in value chain networks (Wilkesmann \& Wilkesmann, 2018). Furthermore, ongoing technological innovations will start the shifts on changing markets, division of labor, organization structure and so forth. The organization structure concentrates on more customer needs rather than only increasing outputs and productivity. With an increasing buyers market, manufacturing companies are forced to differentiate their products and eliminate waste along their value chains by implementing lean strategies (Sanders et al., 2016). That will also lead to decrease product lifecycles where organization structures deal with huge complexity (Brettel, Friederichsen, Keller \& Rosenberg, 2014).

Likewise, through major shifts in industrial production, value chains, market changes and organization structures, the companies are likely to maintain their competitiveness with new ways of thinking, by new ways of organizing, value chain integration, focusing on more core competences resulting in structuring new business models (Szalavetz, 2018; Porter \& Heppelmann, 2014). The usage of digitalization will lead to some alterations both in organizational and network level for enterprises, especially the patterns of how they communicate with their employees and customers and where they position themselves in the market (Castelo-Branco, Cruz-Jesus \& Oliveira, 2019). Therefore, the competitive pressures will affect the companies' decisions by either maintaining their existing business models or adapting the new business models via automation.

Today, the main concern for companies is to find a way to achieve a sustainable, competitive advantage in a transformative industry structure. In order to achieve competitive advantage, a firm can differentiate itself from its competitors by making trade-offs between premium price and lowering costs. This would lead to achieve profitability and growth compared to the industry average (Porter \& Heppelmann, 2014). The concept of Industry 4.0 presents the adoption of IT techniques such as cloud computing, big data, and Internet of Things to gain competitive advantages in both domestic and global markets (Castelo-Branco et al., 2019). The growing potential of the competitive landscape in manufacturing also affects nations' competitiveness (WEF, 2018). Therefore, the purpose of this paper is to clarify the main attributes of competitiveness in the manufacturing industry on Industry 4.0 development by using Porter's Diamond Model. This well-known and powerful model stated by Porter (1990) provides a framework to define the competitive advantage of nations based on the industrial clusters of their companies (Asmussen, Pedersen \& Dhanaraj, 2009). Moreover, the study shows the degree of perceptions of manufacturing companies about Industry 4.0 such as how they define the concept, its technologies, and its effects to their industry. Concerning the arguments above, the present research aims to give answers to the following two research questions:

RQ1: To what extent are manufacturing companies in Turkey aware of the concept of Industry 4.0 and its technologies? In order to answer this question, the research shows the familiarity of manufacturing companies with the term Industry 4.0 and its technologies, and their perspectives about the effects of Industry 4.0 for their industry.

RQ2: What are the aspects of achieving a competitive advantage on the path of Industry 4.0 development in Turkey? Here, the research shows the opinions of manufacturing companies in terms of the determinants of competitive advantage based on Porter's Diamond Model (factor conditions, demand conditions, related industries, and firm strategy and rivalry).

To elucidate these research questions, the paper presents an exploratory research design by applying semi structured interviews from 14 representatives of the heavy manufacturing industry within the following sectors: electrical equipment, machinery, and metals, as these three sectors refer to around $17 \%$ value added into the manufacturing industry in Turkey (MAKFED, 2018). This research is structured in 6 sections. Section 2 explains the framework of the Porter Diamond Model and the definitions of Industry 4.0 proposed in the literature. Section 3 describes the 
research design and the empirical settings of the paper. Section 4 presents the results of the analysis. Section 5 discusses the supported factors, government role and chances, for the determinants of competitiveness while the final section comprises the conclusions and recommendations for further studies.

\section{Literature Review}

\subsection{Revision of Diamond Model}

The Diamond Model was selected for a qualitative analysis in order to provide a process view idea for value chains. According to Porter (1990), 'the diamond model' offers an investigation on why nations have a competitive advantage in particular industries. Furthermore, the research states that the competitiveness of a particular nation depends on a level of productivity that companies can accomplish from their location (Kharub \& Sharma, 2017). Therefore, the model emphasizes four attributes on nations' competitiveness: factor conditions, demand conditions, related and supporting industries, and firm strategy, structure and rivalry. Additionally, these determinants are extended by "chance" factors and 'government policies.' The model is a key tool, as it provides many feasible results in identifying indices, impacting the competitiveness of nations (Chung, 2016).

\subsubsection{Factor Conditions}

Porter (1990) expressed that factor conditions are related to factors of production that are adequate to compete in a given industry. According to the research, factor endowments could be classified as broad categories such as human resources, physical resources, knowledge resources, capital resources, and infrastructure (Jin \& Moon, 2006; Kharub \& Sharma, 2017). Unlikely the traditional methods of classification, Porter (1990) examines these factors as namely basic, advanced, generalized and specialized factors. Consequently, the implications of these factors mainly offer competitiveness on a long term basis; therefore, it helps to attract new investors to the region. Put simply, availability of the labor force as well as their educational level and their technical skills which have influence on quality and delivery of manufacturing goods increase customer satisfaction and are counted as giving the companies a long term achievement and boosting new investments in nations (Ajitabh \& Momaya, 2004).

Most scholars attempt to explain factor conditions with labor aspects and capital aspects such as investments of these technologies and their infrastructures, but availability of natural resources in a nation could also effectively forge an advantage of utilizing these factors (Heeks, 2006; Moon, Rugman \& Verbeke 1998; Riasi 2015; Bakan \& Doğan, 2012). Bhattacharjee and Chakrabarti (2015) opine more detailed enumeration of factor conditions; they also add cost arbitrage which means availability of cheaper and quality manpower and resources in a country compared to other nations. In addition, some other aspects that have an impact on labor production could be regarded as factor conditions. For example, satisfaction level of employees might also affect the degree of productivity (Nanda \& Singh, 2009). Although these factors are lying on the central point of the model, the basic factors can be undermined according to their necessity or availability on selected industries (Fang, Zhou, Wang, Ye \& Guo, 2018).

\subsubsection{Demand Conditions}

Traditionally, this determinant refers to the size of a local market. The competitive edge could be determined whether home demand is high or not. The higher demand leads in forcing companies to meet higher standards such as upgrading technology, quality improvement, and higher production performance with better services (Kharub \& Sharma, 2017). Porter (1990) also emphasizes that the sophisticated demand of customers could generate industrial competitiveness. Actually, sophistication plays a more significant role than market size in some cases (Lin, 2011; Bakan \& Doğan, 2012). According to Barnard and Tuomi (2008), demand sophistication is associated with complexity of demand and specialized customer requirements; therefore, it is necessary for economic upgrading. Porter (1990), however, explains that a minimum quantity of local demand is adequate to develop the sector at any rate; even so, the quality of demand which refers to the complexity of product or service features that meet particular customer expectations is also an important aspect to stimulate competitiveness of nations.

Moon et al. (1998) argue that sophisticated demand results in a nation's companies to adopt new technologies faster, and such technologies would attract new investments with their efficient facilities. On the other hand, when 
the companies in a nation have more diversified markets in the world, this also leads to sophistication on the demand side. The development of value added services and their efficiency increase customer satisfaction, Just In Time (JIT) activities, and effective usage of available resources (Rojaka, 2015, Petrakis, Kostis \& Valsamis, 2015). Therefore, the service efficiency level could also be considered as an indicator of demand conditions (Chung, 2016; Kharub \& Sharma, 2017).

\subsubsection{Related Industries}

The proximity of related companies and industries operating could encourage firms to compete. The supporting industries offer innovations and motivations for upgrading of components, materials and processes (Brosnan, Doyle \& O’Connor, 2016).

The presence of effective support by co-companies is a significant factor in gaining competitiveness. Those activities can be considered marketing, distribution, and interaction across companies and businesses. (Esen \& Uyar, 2012). Porter (1998) explains the 'advantage that home-based related and supporting industries provide in innovation and upgrading; in other words, close working relationships resulting in quick communication and flow of information between partners and exchange of ideas and innovations are giving several advantages to companies in terms of competitiveness. Companies could benefit in accelerating their long-term achievements by encouraging technical efforts of their suppliers, and sharing information with them (Porter, 1990; Bridwell \& Kuo, 2005). The close relationship with suppliers improves value chain activities since the companies coordinate and share their activities. These industries may have strong backward and forward linkages with the firms in a given sector. (Moon et al., 1998)

\subsubsection{Firm Strategy and Structure}

The final determinant of the model is related to the contributions of organizations with domestic rivalry. This is important in increasing regional competitiveness (Brosnan et al., 2016). The effects of global economic integration have shifted the competition between companies from pricing to branding, which refers not only to the economic strength and market reputation of the companies but also to the whole industry's international competitiveness. Therefore, the level of investment in research and development activities, independent product design, and strengthening the talent pool have an effect on building a company's brand and strategy (Guan, Xu, Jiang \& Jiang, 2018).

According to Porter and Heppelmann (2014), the unique value set to customer needs determines the companies' decisions of what to do or what not to do. Therefore, companies are first required to decide which choices would give real value to customers relative to their cost. In addition to cost, a number of factors are strategically important such as response time, network availability (confidential data), nature of user interface, and frequency of service or product upgrades.

Porter (1990) argues that domestic rivalry is the pioneer for rivalry with foreign competitors. Moon et al. (1998) explains this argument could be true if the economies are large such as The United States; however, it is not always true for developing countries. These countries also need to concentrate on international rivalry rather than domestic rivalry. Therefore, openness of foreign products is fundamental for international rivalry.

\subsection{Industry 4.0 Definition}

The concept of Industry 4.0 was first coined as a German project with the objective of identifying a highly digitized manufacturing process in which information flows among machines controlled by humans; in doing so, human intervention is decreased to a minimum (Castelo-Branco et al, 2019). Many authors indicate that there is no commonly agreed-upon definition of Industry 4.0 (Hofmann \& Rüsch, 2017; Ghobakhloo 2018; Lasi et al., 2014; $\mathrm{Lu}, 2017)$.

Brettel et al. (2014) explains that Industry 4.0 concentrates on developments of intelligent products and production process. Therefore, manufacturing companies need to adapt to rapid product development, flexible production as well as complex environments. The study shows the concept of Industry 4.0 is also connected to smart factory and Cyber Physical Systems (CPS) which enable the communication between humans, machines and products alike. 
Wilkesmann and Wilkesmann (2018) clarify that most fields of Industry 4.0 are still in the developmental phase. They believe that most applications do not encompass the initial definition of Industry 4.0 since they provide single solutions which do not cover all aspects in terms of self-organized value-creation networks. Wang, Wan, Li and Zhang (2016) explain that all industrial revolutions emerge because of people's needs and lead to develop people's living standards, provide customized and high quality products to customers and create better working environments for employees. According to the study, the principle of Industry 4.0 is to set up emerging technologies to implement Internet of Things (IoT) and services by integrating the business and engineering process in order to make production as flexible and efficient with consistent high quality and low cost.

\begin{tabular}{|c|c|}
\hline Authors & Definitions on Industry 4.0 \\
\hline Castelo-Branco et al., 2019 & $\begin{array}{l}\text { 'Industry } 4.0 \text { is ... Structural changes in production processes potentiated } \\
\text { disruptive innovations and paradigm changes that had strong impacts in } \\
\text { productivity and eventually created the conditions for new business models' }\end{array}$ \\
\hline Brettel et al., 2014 & $\begin{array}{l}\text { 'Industry } 4.0 \text { focuses on the establishment of intelligent products and production } \\
\text { processes. Within the factory of the future... CPS will enable the communication } \\
\text { between humans, machines and products alike' }\end{array}$ \\
\hline Sanders et al., 2016 & $\begin{array}{l}\text { 'Industry } 4.0 \text { is applying the principles of cyber-physical systems (CPS), internet } \\
\text { and future-oriented technologies and smart systems with enhanced human- } \\
\text { machine interaction paradigms' }\end{array}$ \\
\hline Hermann et al., 2016 & $\begin{array}{l}\text { Industrie } 4.0 \text { as "a new level of value chain organization and management across } \\
\text { the lifecycle of products" }\end{array}$ \\
\hline Lu, 2017 & $\begin{array}{l}\text { 'The goals of Industry } 4.0 \text { is.to achieve Io'T-enabled production optimization in } \\
\text { smart factories; and to provide new types of services and business models of } \\
\text { interaction in the value chain' }\end{array}$ \\
\hline Hoffman and Rüsch, 2017 & $\begin{array}{l}\text { 'The Fourth Industrial Revolution can be best described as a shift in the } \\
\text { manufacturing logic towards an increasingly decentralised, self-regulating approach } \\
\text { of value creation, enabled by concepts and technologies such as CPS, IoT, IoS, } \\
\text { cloud computing or additive manufacturing and smart factories, so as to help } \\
\text { companies meet future production requirements' }\end{array}$ \\
\hline Kolberg and Zühlke, 2015 & $\begin{array}{l}\text { 'Driven by modern information and communication technologies (ICT), Industry } \\
4.0 \text { is a network approach where components and machines are becoming smart } \\
\text { and a part of a standardized network based on the well proven internet standards' }\end{array}$ \\
\hline Wang et al, 2016 & $\begin{array}{l}\text { 'In order to preferably implement Industrie } 4.0 \text {, the following three key features } \\
\text { should be considered: horizontal integration through value networks, vertical } \\
\text { integration and networked manufacturing systems, and end- to-end digital } \\
\text { integration of engineering across the entire value chain' }\end{array}$ \\
\hline Lasi et al., 2014 & $\begin{array}{l}\text { 'The vision of future production contains modular and efficient manufacturing } \\
\text { systems and characterizes scenarios in which products control their own } \\
\text { manufacturing process' }\end{array}$ \\
\hline Wilkesmann and Wilkesmann, 2018 & $\begin{array}{l}\text { 'The vision of Industry } 4.0 \ldots \text { linkage of production processes, starting from the } \\
\text { customer's order, through the creation of production processes, to downstream } \\
\text { product services' }\end{array}$ \\
\hline Drath and Rosch, 2014 & $\begin{array}{l}\text { 'The term Industrie } 4.0 \text { is often understood as the application of the generic } \\
\text { concept of cyberphysical systems (CPSs) to industrial production systems (cyber } \\
\text { physical production systems)' }\end{array}$ \\
\hline
\end{tabular}

Table 1. Extent definitions of Industry 4.0

Industry 4.0 is mostly combined with the concept of CPS production which is integration of data and knowledge. The main principles of CPS are to achieve the agile and dynamic requirements of production and to develop the effectiveness and efficiency of production (Lu, 2017). Kolberg and Zühlke (2015) describe the term of Industry 4.0 as a network approach driven by modern information and communication Technologies (ICT), which enable the 
components and machines with a smart and standardized network with proven Internet standards. Lee, Bagheri and Kao (2015) show the requirements of a clear definition of the structure and methodology of CPS as guidelines for its implementation in industry. For this reason, a unified system framework must be completed for general applications. With the help of algorithms and technologies at each system layer, the overall system will collaborate and accomplish the desired functionalities of the overall system with efficiency, reliability and product quality. Hofmann and Rüsch (2017) approach the concept with manufacturing logic towards a self regulating approach of value creation and driven by technologies such as CPS, Internet of Things (IoT), cloud computing or additive manufacturing and smart factories to achieve future production requirements. According to the definition by Hermann, Pentek and Otto (2016), Industry 4.0 covers the technologies and concepts of a value chain as well as creating a virtual copy of the physical world and making decentralized decisions. IoT and CPS are the major components of this concept for value chain participants and humans to communicate and cooperate in real time.

Although Industry 4.0 is currently a popular term for many organizations, research centers and universities, manufacturing firms face challenges in understanding this phenomenon and designing the necessary steps required for the transition toward Industry 4.0 (Ghobakhloo, 2018). Table 1 demonstrates an overview of the definitions of scholars from literature regarding Industry 4.0.

\section{Methodology}

An exploratory, qualitative approach based on semi structured interviews was considered the most convenient method to analyze this research. The qualitative method of the research augments issues related to generalizing the results (Müller, Buliga \& Voigt, 2018). To answer such issues, the sample of companies interviewed was selected based on two criteria: the first was to select manufacturing companies with more than fifty employees and revenue is higher than 4 million dollars (around 25 million TL in the local currency, 1 dollar= 6.13 TL) according to the definition by the Turkish institute (TOBB) on medium and large enterprises. Therefore, the research excluded micro and small-sized companies because the proposed models on Industry 4.0 still do not fit the specific requirements of small-sized companies (Mittal, Khan, Romero, \& Wuest 2018). The second criteria was to include three sectors from the heavy manufacturing industry and user cases. A random selection method was employed in the selection process of the companies which are only located in the Izmir region of Turkey. Based on the initial selection, 70 enterprises were determined. The emails were sent to departments of interest such as production, operations management, supply chain, information systems as well as to CEOs and general managers. Consequently, there were fourteen medium and large-sized companies included in the research representing machinery, metals and electrical equipment since they were willing to attend the interviews.

The respondents were selected from CEOs, general managers, plant managers, general directors, project managers and information systems managers. Out of the 14 companies, eight are medium enterprises with more than 50 and less than 250 employees, and their annual turnover is more than 4 million dollars and less than 20 million dollars; six are large companies with more than 250 employees and an annual turnover higher than 20 million dollars.

The experience of the respondents in their qualification range between 1 year to 46 years. Lasting between 30 and 90 minutes, the interviews were conducted between August and October 2018 mostly via on-site visits to the companies, only two of them via video conferences. All of the interviews were recorded on audio files and were later transcribed into Word files. Table 2 demonstrates the characteristics of the sample respondents and the companies $(\mathrm{N}=14)$ represented in this study.

The guidelines of the interview are comprised of three sections: in the first one, the respondent briefly explains the main activities of the company and his leading role in the company. In the second section, the questions about Industry 4.0 were asked to the respondent. Here, the respondents understanding of the concept, its main technologies and its impacts on their company/industry were analyzed. Eventually, the definitions of the literature and the respondents' answers relating to Industry 4.0 were compared. In the last section, it is competitiveness model centered; therefore, the respondents were expected to explain what kind of attributes affect their companies on Industry 4.0 development. Here, the questions were based on Porter's Diamond Model Framework, so the respondents were asked questions about factors of production, demand conditions, their 
partners and related industry, and about the strategy of the firm to gain a competitive advantage while developing Industry 4.0 practices.

Data taken from the interviews were also compared with the companies' websites, the related press interviews on the concept. This provides clearer comprehensions about the companies as well as the validity of the study. Based on the literature, coding manual was improved. Through hand coding, iterative patterns were identified from written scripts. Therefore, the main differences and similarities were examined via cross-case analysis after the codes taken from each respondent. The data and codes inductively improve the structure of the study related to the concept of Industry 4.0 and the dimensions of competitiveness.

\begin{tabular}{|l|c|c|c|c|}
\hline & Sector & Position of The Respondent & $\begin{array}{c}\text { Employee } \\
\text { Number }\end{array}$ & Revenue/Yearly \\
\hline Company 1 & Metals & General Manager & $50-100$ & $4-10$ M dollars \\
\hline Company 2 & Electrical Equipments & Plant Manager & $50-100$ & $4-10$ M dollars \\
\hline Company 3 & Electrical Equipments & General Director & $50-100$ & $4-10$ M dollars \\
\hline Company 4 & Machinery & General Manager & $50-100$ & $4-10$ M dollars \\
\hline Company 5 & Electrical Equipments & General Manager & $50-100$ & $4-10$ M dollars \\
\hline Company 6 & Machinery & General Coordinator & $50-100$ & $10-20$ M dollars \\
\hline Company 7 & Electrical Equipments & Information Systems Executive & $50-100$ & $10-20 \mathrm{M}$ dollars \\
\hline Company 8 & Electrical Equipments & Information Systems Manager & $100-250$ & $10-20 \mathrm{M}$ dollars \\
\hline Company 9 & Machinery & General Manager & $>250$ & $20-125 \mathrm{M}$ dollars \\
\hline Company 10 & Metals & Information Systems Executive & $>250$ & $20-125 \mathrm{M}$ dollars \\
\hline Company 11 & Machinery & Production Manager & $>250$ & $20-125 \mathrm{M}$ dollars \\
\hline Company 12 & Metals & Information Systems Manager & $>250$ & $20-125 \mathrm{M}$ dollars \\
\hline Company 13 & Metals & Plant Manager & $>250$ & $>125 \mathrm{M}$ dollars \\
\hline Company 14 & Electrical Equipments & Project Manager & $>250$ & $>125 \mathrm{M}$ dollars \\
\hline
\end{tabular}

Table 2. The Characteristics of the Sample Companies and The Respondents (N=14)

\section{Results}

\subsection{Understanding the Term of 'Industry 4.0'}

According to the interview guideline, the first and second interview questions are related to the familiarity of the respondents with the term Industry 4.0. The main insights are taken from the analysis: two of the respondents barely have any knowledge of Industry 4.0; six of them have general knowledge, and the rest of the respondents have a detailed definition of the term. The respondents show that they are well informed on the concept and gave extensive and more detailed definition, as an example, 'The process which can be used through advanced technologies, by using minimum human work and decreasing defect rates on all value chain activities. The important point is also not just taken these technologies, also standardized those technologies on the process through partners.' Another example, 'Industry 4.0 is a new revolution triggered by Germany; although it starts on manufacturing industry; however, now it spreads most of the sectors. By increasing human-machine collaboration, monitoring the systems via accurate communication between partners, it will help companies create autonomous environment by giving efficiency and flexibility in their operations.' Through the analysis, the most well-known respondents' answers were coded as the definition of Industry 4.0 as the following: 1) advanced technologies appeared in manufacturing activities 2) autonomous and self-controlled systems created by reducing human work 3) integration of supply chain partners. Some of them also focus on the possible outcomes of Industry 4.0 such as, increasing speed, efficiency, optimization, and productivity. However, the respondents who are thought as less informed about the concept are likely to show the negative effects of Industry 4.0. One of the examples from one of the less informed respondents' states that 'Technology is a good thing but it always increases our costs rather 
than our revenues.' Those informants do not tend to indicate the detail description about the concept and only use the definition of Industry 4.0 as 'technology' and 'TT'.

Surprisingly, through the second question which is related to the 'familiarity with the technologies of Industry 4.0,' only three respondents could give detailed information about Industry 4.0 technologies; those respondents mostly noted that Industry 4.0 could be explained with advanced technologies (Big Data, Artificial Intelligence, cloud systems, advanced simulations, 3D printings, advanced robots and so on). Half of the respondents $(N=7)$ explain the technologies of Industry 4.0 with generic terms such as robots, machinery, advanced software interfaces, data management, sensors and so on. The less informed respondents $(\mathrm{N}=4)$ only mention ERP technology, production machines, computer programs, and data analysis methods. They have more of a tendency to explain the concept with traditional technologies.

The third question is to evaluate whether their industry is affected or will or will not be affected through Industry 4.0. Three of them believe that they are already pioneers in the sector and well affected by Industry 4.0. Eight of the respondents answer that their companies are affected in general, but ongoing investments will still give them more bearable changes in 1-2 years. On the other hand, three of them do not believe that Industry 4.0 will affect them in the short term; they need at least a 5-10-year period in order to see main alters in their industry.

\subsection{The Determinants of Competitiveness and Their Effects to Industry 4.0 Development}

To show the effects of the determinants on Industry 4.0 to gain competitive advantage, the remaining part includes the related findings on the determinants of competitiveness, what are factor conditions, demand conditions, related industries and firm strategy.

\subsubsection{Factor Conditions on Industry 4.0 practices}

Labor Factor: Pointing out the findings based on the interviews, labor is the most significant factor among the respondents. All of the respondents believe that many changes will happen on the human side as a consequence of Industry 4.0. The first concern is occupational structures in the future; almost one third of the respondents $(\mathrm{N}=4)$ believe that more job creations will occur rather than job losses. Additionally, the workers will benefit from the increase in their qualifications, knowledge and motivation due to the more qualified jobs created. Physical activities of workers will be eased by the increase of brain jobs. Half of the respondents have the opinion that job losses will be much more than job creations. Only white-collar employees will benefit from those job creations while blue collar employees will be the most affected type of employees from certain job losses. The rest of the respondents $(\mathrm{N}=3)$ opines that all types of employees will be affected due to the effects of full automation. According to them, only few people might be employed for the high qualified positions, and with even more automation, these people might also be eliminated. In addition, six of the respondents mention the negative effects on employees' motivation through automation. One of the examples from the respondent opinion states, 'For assembling process in our factory we used to have eight employees but now, we only need two employees for this process. Therefore, employees have a fear of losing their jobs and this results in losing their motivation on the production process.'

Commonly, most of the interviewees $(\mathrm{N}=9)$ perceive that adaptation of their employees in the short term is the most challenging factor for new technologies. As one respondent explained, We find it difficult to adapt our workers for such technologies. It takes minimum six months to make them fully adapted and experienced on that; therefore, it is time consuming and costly for the company.' Another respondent stated, 'People do not want to change their working habits or they do not accept the technologies because they have a fear of losing their jobs in the future.' However, some respondents $(\mathrm{N}=3)$ see the opportunities to work with a new generation through their interaction with technologies; therefore, this will give more technological achievements in the near future to their companies. On the other hand, some of them $(\mathrm{N}=5)$ mention that the challenge is to find the qualified employees for these technologies. One of the informants explained, 'Well, we can invest these technologies, but who is going to use them? We do not believe there is enough competition on the labor market for them. So we are not sure that the best person will be selected for the certain positions to use these 
technologies.' Also, three of them explain that education is a crucial factor for improving skills of the employees on the adaptation of digitalization. Half of them mention that they have certain trainings for introducing the new technologies to their employees.

Capital Factor: Here, the informants explain high investments of these technologies and IT infrastructure seems costly in a short term. Almost all of them mention that they only take a required technology for their operations area where they would like to improve and bring them higher return on investments (ROI) in 1-2 years maximum. High installation costs as well as upgrading of these technologies are the main concerns of the capital factor among the respondents. An example from one of the respondents states, 'Investing these technologies could be so expensive in our market (in Turkey), because we have to outsource these technologies rather than producing in our country. Also, the extra costs are generated such as taxes, the costs of administration and third parties and etc.'

Furthermore, companies believe that technology is changing so fast that they could not make a long term plan for their tradeoffs (costs and prices). The respondents $(\mathrm{N}=4)$ indicate that the IT softwares and interfaces are upgraded on average every 6 months to 1 year. Therefore, after they invest these technologies, their dependency to the technology producer also rises.

Also, two of the respondents argue that investing Research and Development (R\&D) activities are costly for the companies due to the requirements of high technical skills and qualified employees who worked on it. On the other hand, some of the respondents $(\mathrm{N}=4)$ view that the usage of technology now makes it easier to achieve these activities because of its time efficiency and is less costly in a long term.

Openness to innovation: Another point drawn by the respondents is the importance of a technology driven culture. Almost all of the respondents advocate the openness of the upper levels such as CEOs, managers and directors to innovation is quite significant in accepting these kinds of technologies. They point out that there are a certain number of family based companies in Turkey; they tend to not use ITs because of their lack of expertise. Specifically, the respondents claim that convincing the upper levels takes a lot of time for implementation of ITs because they are not likely to see the benefits behind it. One of the CEOs among the respondents states, 'I have attended one of the meeting related to Industry 4.0 and there was a discussion about whether it is enough to train employees or also employers. The result was that just training the employees would not make you escape from a failure.'

Another concern also taken from some respondents $(\mathrm{N}=4)$ is the gap between employers and employees due to their age differences. They noted that the upper levels found it easier to use traditional methods rather than using technology because of their working habits in the past. One of the respondents explained, 'For example, it is hard to change the working habits of my boss. Even he finds easier to write the notes after regular meetings into a paper rather than using computers.' Almost half of the respondents agree that their organizations are open to innovation, but there are still ongoing problems to overcome in their culture.

Natural Resources: Only few respondents $(\mathrm{N}=3)$ believe that technology will increase their organizations' energy consumption as well as increase the costs especially in developing countries. Unless countries encourage the production of renewable energies for these technologies, it will result in energy inefficiency for manufacturing organizations in particular. An example from a respondent says, "Today the biggest shortage of our economy is energy such as oil and electricity. So when you start to use these technologies, that will rise your variable costs such as using more electricity and oil. Therefore, developing countries which are less tend to produce energy will not be benefited enough from these technologies.'

\subsubsection{Demand Conditions on Industry 4.0 practices}

Demand Size: The respondents expect to increase their sales and reach larger markets through the benefits of Industry 4.0. The advanced technologies enable organizations to easily find customers or to promote their products and services online. The most notable thing among the findings is that gathering customer data into companies' databases is absolutely important for many organizations due to raising transparency and easily meeting with customers' requirements. One of the respondents mentioned, 'There is a remarkably time efficiency on holding 
customer data via Customer Relationship Management (CRM) databases. Our company gathers the data about types of products that customer chooses, in what price ranges they want to buy the products or what kind of payment methods they choose. In this way, we can overlook a current performance of each customer.' In addition, some of the respondents show that to reach a large number of customers, social media needs to be effectively used, and companies' promotions via Search Engine Optimization (SEO) programs need to be enhanced. These respondents claim that reaching a large market is getting easier via technologies, and employees do not have to put more effort into this anymore. Also, more transparency generated on the customer side is an important aspect in capturing the trustworthiness of the targeted customers.

Although most of the respondents are aware of the importance of implementing data management techniques on the customer side, the utilization of advanced data techniques in a real time manner is still observed on average among the sample companies $(\mathrm{N}=7)$.

Customer Sophistication: The respondents have diverse opinions on 'selling bigger or selling to trustful customers.' Some respondents $(\mathrm{N}=5)$ would like to improve the quality and loyalty of customers rather than increasing more sales. One respondent explained, 'Before we wanted to sell the products to the more customers; however, now we want to sell them to trustful customers and get the money on the expected time.' Half of the respondents believe that their customers' interest in using online communication channels is growing. Their customers would like to check the companies' webpages, the products' specialties that companies offer or order the products online. Actually, some companies $(\mathrm{N}=3)$ mention that their customers demand the use of online channels or cloud systems more than using traditional methods such as telephone calls and emails. Also, one respondent explained, 'Now technology enables transparency which makes easier to convince the customers in market for our products or service offers. So, in the future the competitiveness will be higher, because more transparency will exist about what we are selling.'

With technological increases, the companies could focus more on customized needs rather than economies of scale. Therefore, there might be a decrease in batch sizes. However, mass customization activities would not be standardized in a short term. Many respondents $(\mathrm{N}=9)$ believe that their companies would not achieve mass customization processes in a short term, at least 5-10 years would be needed for that.

Service Efficiency Level: Also, many respondents $(\mathrm{N}=10)$ opine that using these technologies will increase the quality and flexibility of the services given to their customers. As a result of this, a number of satisfied customers would increase. Here, the companies also need to focus on after sales services offered by technologies which increase the level of efficiency and flexibility in their services through customer feedback. One example states, 'Using cloud systems on after sales services creates more satisfied customers. We get many positive feedbacks about this. Because we can easily handle with the situation anymore. Also, we gather the reviews of our customers in a database, which is a process of big data to analyze and forecast the requirements of our customers.'

It has been observed that only three companies are highly investing in big data technology; the rest claim that they use less advanced data management techniques to analyze the processed data for forecasting activities.

\subsubsection{Related Industries on Industry 4.0 practices}

Suppliers: Using digital technologies helps the companies increase their supplier selection activities. As evidence of that, the respondents $(\mathrm{N}=9)$ highlight that they can easily classify suppliers in terms of their previous performances in certain activities and also by monitoring the price/service ratio of the selected suppliers. Mostly, these activities are not simple to do without digital systems. One of the respondents expressed, 'We can evaluate suppliers' capabilities and performances which make you more competitive in your industry.'

In addition, improving digital capabilities of the suppliers is still viewed as being easier for many companies rather than replacing them with the new one $(\mathrm{N}=7)$. However, that is related more to the sharing of ideas about the new trends and encouraging them to implement these technologies rather than training them. Likewise, the respondents $(\mathrm{N}=10)$ indicate that supplier communication is crucial in monitoring all activities in both the procurement and production sides and in responding to the changes. Effective communication with suppliers is also significant in achieving trust and building a long term relationship between supplier and manufacturer. Advanced software 
interfaces and common platforms increase real time information sharing and agility activities in many areas. The respondents $(\mathrm{N}=7)$ advocate that technological capabilities and investments of $\mathrm{R} \& \mathrm{D}$ activities of their suppliers are very significant for them. Also, some respondents $(\mathrm{N}=5)$ state that they could replace their suppliers if they do not adapt IT capabilities in a short term.

Most of the companies (N=9) use ERP systems to communicate with their suppliers; however, it is hard to say that they use real time ability systems. Upon observation, only three companies are already using advanced interfaces for communicating with their suppliers. The main challenge is to standardize these systems for real time communication.

Research Institutes: Only few respondents $(\mathrm{N}=4)$ advocate that their organizations collaborate with universities, research institutes, etc in terms of developing Industry 4.0 projects. Out of the 4 respondents, they mostly refer to these projects related to improving data management techniques, increasing the efficiency of ERP systems, or in effectively monitoring production systems. However, they indicate that these projects are not only limited to these activities, but they also depend on the companies' strategies, KPI factors and key benefits gained by implementing the particular technologies.

\subsubsection{Firm Strategy on Industry 4.0 practices}

Several prerequisites should be employed to develop Industry 4.0 strategy as explained by the respondents. First of all, enterprises need to plan their short and long term objectives through roadmaps before operating the digital technologies. This would also allow them to review their Key Performance Indicators (KPIs), which displays how effectively their organizations accomplish their key business targets. Similarly, having roadmaps for the utilization of these technologies indicates the specific requirements and main challenges faced with digitalization. By considering strategic planning activities, organizations could evaluate their capabilities, current performances and enabling factors to apply to a particular technology. One of the respondents gave an example related to this, 'We attempt to establish digital twin technology for our manufacturing system; therefore, through roadmap we revise our production system again. It was good to identify possible challenges and main benefits if we use this technology and what are the missing factors in our production system.' Therefore, the roadmaps and frameworks are mostly defined by the targeted needs of the companies.

Secondly, organizations should allocate their financial resources effectively for certain tasks and technologies because they heavily rely on their financial capabilities and return on investments (ROI) to improve their performances. The decisions about what kind of investments would depend on KPI factors and how well companies could afford to improve these KPIs. According to the respondents, when the companies make short or long terms plans, they need to consider their financial availability for certain activities such as how many employees could work on that, how much should be allocated for R\&D activities, and what steps should be taken to accomplish these activities.

Finally, it is essential that enterprises require to adapt their employees to their strategies and roadmaps. Employees must be informed about the objectives and action plans of certain projects and trained for certain tasks. As an initial step, companies could start with periodic meetings and conferences to inform their employees about the effects of digitalization and what companies would like to achieve while implementing Industry 4.0. According to one of the respondents, 'As mentioned previously, our employees had a fear of losing their jobs; however, our company described our strategies to them clearly, now we can see that they are motivated toward using these technologies because they started to understand that a main point is not to fire them, conversely, is to reduce their workload.' Some respondents consider that there might be some job losses through automation; however, their pioneer reason for using these technologies is to cut the operation costs such as reducing defect rates, costs of materials or improving lead times rather than reducing labor costs.

Although Industry 4.0 must also be viewed as a part of strategic planning, only five of the respondents indicate that they already have or work on the roadmaps toward Industry 4.0. Also, the time period of achieving their strategies is ranging between 6 months to 3 years based on whether they are tactical or strategical.

The summary of the results is illustrated for each determinant in Table 3. 


\begin{tabular}{|c|c|c|c|}
\hline Factor Conditions & Demand Conditions & Related Industries & Firm Strategy \\
\hline $\begin{array}{l}\text { 1. Labor Factor } \\
\text { - Changes on occupational } \\
\text { structures } \\
\text { - Employee motivation and } \\
\text { efficiency } \\
\text { - Adaptation of employees } \\
\text { - Challenges on finding high } \\
\text { qualified employees }\end{array}$ & $\begin{array}{l}\text { 1. Demand Size } \\
\text { - Level of reaching more } \\
\text { markets through online } \\
\text { channels } \\
\text { - Handling with complexity } \\
\text { on demand size }\end{array}$ & $\begin{array}{l}\text { 1. Suppliers } \\
\text { - Supplier Selection } \\
\text { - Supplier } \\
\text { Knowledge } \\
\text { - Supplier } \\
\text { Communication }\end{array}$ & $\begin{array}{l}\text { 1. Roadmaps } \\
\text { - Defining short and long } \\
\text { term plans, identifying } \\
\text { benefits and challenges }\end{array}$ \\
\hline $\begin{array}{l}\text { 2. Capital Factor } \\
\text { - Installation Costs and } \\
\text { Investments } \\
\text { - Upgraded softwares and } \\
\text { interfaces } \\
\text { - Technical costs and R\&D }\end{array}$ & $\begin{array}{l}\text { 2. Customer Sophistication } \\
\text { - Size of quality customers } \\
\text { through transparency } \\
\text { - Achieving customers } \\
\text { specific needs through } \\
\text { customization }\end{array}$ & $\begin{array}{l}\text { 2.Research Institutes } \\
\text { - Develop Industry } \\
4.0 \text { projects }\end{array}$ & $\begin{array}{l}\text { 2. Financial Availability } \\
\text { - Investments and ROI }\end{array}$ \\
\hline $\begin{array}{l}\text { 3. Culture/Knowledge and } \\
\text { Skills } \\
\text { - Willingness of upper levels } \\
\text { on digitalization } \\
\text { - Age gap }\end{array}$ & $\begin{array}{l}\text { 3. Service Level } \\
\text { - Quality } \\
\text { - Flexibility } \\
\text { - Methods of Forecasting }\end{array}$ & & $\begin{array}{l}\text { 3. Employee Trainings } \\
\text { - Periodic meetings and } \\
\text { conferences } \\
\text { - Informing them for } \\
\text { certain tasks }\end{array}$ \\
\hline $\begin{array}{l}\text { 4. Natural Resources } \\
\text { - Energy Shortage }\end{array}$ & & & \\
\hline
\end{tabular}

Table 3. The Factors That Affect Industry 4.0 Competitiveness Based On The Interviews

\section{Discussion}

\subsection{Government Role on Industry 4.0 Practices}

Last year, Turkey witnessed economical disruptions due to the effects of high inflation and interest rates, and Turkish currency, the lira, has lost about $30 \%$ of its value against the US dollar. This has increased the vulnerability on the manufacturing industry because many Turkish firms have borrowed in foreign currency which is more expensive when it comes time for repayment. Furthermore, this makes imports more expensive as well as the digital investments in the country. Therefore, the respondents advocate that challenges to the economy would suspend investments on advanced technologies unless it is fixed in a short term by the government. On the other hand, the government attempts to take some necessary steps to avoid the challenges; also, last year it was announced that there were new economic plans which cover the macroeconomic targets such as price stability, economic balance and fiscal discipline between 2019-2021. The country still expects $2.3 \%$ economic growth in the following year. Additionally, as part of Turkey's 2023 economic plan, the country would like to boost the economy by domestically producing high valued technological equipment. Last year, the country also announced its roadmap on Industry 4.0 which consists of the targets on six constituents: human, technology, infrastructure, suppliers, users and governance. According to the content of human target, the country would like to improve employees' educational levels and a number of qualified labors. In this perspective, users of technology will be raised in technical schools; the education programs will be supported with technology; and the labor force will be supported with trainings at pilot companies. As technological improvements, the target is to increase the capacity on technology and innovation. Therefore, the country plans to prepare the roadmaps of each technology for Industry 4.0 (Artificial Intelligence, Big data, Advanced Robots and so on). Also, entrepreneurs on digitalization will be supported, and practical oriented centers will be established. The objective of infrastructure is to raise data communication systems and their infrastructure. Therefore, there are some incentives for manufacturing companies which use technology such as increasing internet speed, cyber security and so on. Also, the country plans to start using 5G technology in a short time. For the suppliers, the country tends to support the national suppliers in technology production. The country helps national technology suppliers access long term funding. In addition, technology fairs will be organized to facilitate interaction between technology and manufacturing companies. On the user side, the main principle is to support the users with digital transformation. Therefore, the pilot research on digitalization will start in industrial 
zones, and many supervisors will be recruited to help manufacturers with their transformation into digitalization. For the governance, it is significant to strengthen the governance of institutions. For this principle, some committees will be constructed in the field of data standardization, focusing technologies and tracking digital trainings and so on.

Over half of the respondents $(n=7)$ mention that the government becomes faster than their companies in digital transformation. These respondents also added that there are some forces from the government to digitally transform their processes.

\subsection{Chances on Industry 4.0 Practices}

Turkey has a large population (reaching to 80 millions); therefore, the market size of the country allows for a significant chance for deploying Industry 4.0. The country's growing young generation could give many opportunities to the labor side. Although it is believed that Industry 4.0 will diminish many jobs, several occupations will also be rendered, especially qualified jobs. Therefore, the contributions to educate and train the young generation could provide a long term, competitive workforce for Turkey.

The effects of the devaluation of the Turkish lira last year make companies concentrate more on exports rather than imports; this also leads to a greater potential to be in demand on the foreign market. From manufacturing companies' perspectives, the products and services offered now are cheaper for foreign customers, so companies could easily reach potential markets through online channels in a less costly way and thus increase their competitive advantage against their competitors.

Furthermore, the government's investments in R\&D activities and their incentives for manufacturing companies in their transformation process to automation could create more potential to the nation's competitive advantage. However, this also depends on how fast the country could solve the vulnerabilities to the economy and increase the capabilities on innovation. The respondents also mention that most of the initiatives are provided to small-sized companies; however, if the pilot projects are started in medium and large enterprises, that would provide higher potentials to the country's economy because they would be the pioneers and help the small- sized companies on their way towards Industry 4.0.

\section{Conclusions}

This paper examines the competitiveness of Industry 4.0 development for manufacturing companies in Turkey based on Porter's Diamond Model. Depending on the perspectives of the respondents from the heavy manufacturing industry, the results of the study can be concluded as the following: firstly, a significant number of medium and large companies have already started their journey towards Industry 4.0 and is aware of the concept. However, it has been observed that Turkey is still in its initial stage in Industry 4.0 competitiveness due to its lack of implementation of Industry 4.0 technologies. Secondly, according to the respondents' opinions, the most important dimension to gain competitive advantage on Industry 4.0 is factor conditions. Employee adaption and finding highly qualified employees for digital technologies are found to be the most challenging factors that affect becoming competitive because the companies found that training the employees is inefficient and time-consuming for them. Another concern is the capital factor. Since these technologies are highly capital intensive, companies do not want to pursue these technologies without their needs. According to the respondents, developing countries are only buying these technologies rather than making them; therefore, it will increase the dependency to the producers of digital products and services.

Thirdly, the companies still give importance to increasing their sales rather than customer sophistication because of the high complexity of producing individual customer needs on the demand side. However, few companies consider that the positive reviews of their customers in online channels could affect their decisions in the near future. In order to increase customer satisfaction, more and more companies could adopt more social media, cloud usage, after sales services etc. As for their suppliers, the companies draw attention to the importance of their suppliers' digitalization. However, there is still no mention of real time communication with their suppliers, nor are they applying advanced interfaces for their communication. This may not be solved in the near future. 
Fourthly, the respondents mention the importance of having a strategy and roadmap to deploy Industry 4.0; however, only a few of them have the detailed plans and roadmaps such as classifying long and short-term strategies, explaining KPIs, and technological investments that must be used for certain tasks. Also, implementing these plans and making them sustainable require a certain amount of time for the companies depending on their type of strategy.

Finally, the macroeconomic instability in Turkey last year has diminished the local demand; however, this could create more foreign demand due to the devaluation of the Turkish lira. Also, the government still has ongoing steps in solving domestic problems and stimulating technological investments in the country. Another chance lies with the country's market size and the growing young generation which may strengthen the labor side in the future due to their high interaction with digital technologies.

\subsection{Recommendations and Future Directions}

Different countries assimilate Industry 4.0 at different levels and patterns. The developed markets dominated by high cost, skilled labor take advantage of high automation whereas developing economies may utilize the opportunities with their young generation; however, they may also completely forge new manufacturing notions.

Manufacturing industry represents the backbone of the Turkish economy; for this reason, manufacturers, their network partners and the government should take precise steps in order to effectively form a digital environment. In regards to the manufacturers, they need to identify which areas they should improve such as productivity, agility, flexibility and set some long-term strategies that would support underlying changes within their organizations. Another point is that they should encourage their workforce to adapt to these technologies by implementing some vocational trainings to bolster their qualifications. It is also essential to involve their network partners to leverage these technologies and build the accurate network structure and capabilities. One of the biggest challenges of utilization of digital systems is to standardize them; therefore, the manufacturers need to enrich their network strategies with their partners as well as jointly employ potential scenarios to identify their long-term achievements.

It is also recommended that government and industry should collaborate together to develop Industry 4.0 standards. Governments could promote digital transformation with decisive policies to embolden enterprises in adopting Industry 4.0 technologies. Besides, they could set specific policies for the improvement of required infrastructure, the development of human resource, and the enhancement of creative innovation capacities. In the case of Turkey, the industry-academia collaboration must be supported through government incentives, and digital trainings of the workforce should also be included into university programs. In addition, technological infrastructures must be upgraded to manage real time data. In the last years, the government also put substantial efforts into this.

This study could give some insights to further research on improving the path of Industry 4.0 competitiveness. There are but a few empirical research on Industry 4.0 competitiveness in nations; therefore, the research also calls more academic works in that field in order to generalize our findings. There are also some limitations of this study. First of all, the research only relies on the perspectives of the heavy manufacturing industry. Further research could also extend the results of this study by applying it to different sectors. Secondly, this study only conducts the interviews with the medium and large companies; therefore, small companies were neglected. Future research may also include small enterprises and put forth their challenges in implementing Industry 4.0 practices. Finally, this study applies in one of the emerging markets, Turkey, to identify the degree of Industry 4.0 applications. However, in different developing countries, the level of adaption and determinants of Industry 4.0 could be changed; therefore, future directions could also examine different developing countries to clearly understand the path of Industry 4.0 and nations' competitiveness.

\section{Declaration of Conflicting Interests}

The author declared no potential conflicts of interest with respect to the research, authorship, and/or publication of this article. 


\section{Funding}

The author received no financial support for the research, authorship, and/or publication of this article.

\section{References}

Ajitabh, A., \& Momaya, K.S. (2004). Competitiveness of firms: review of theory, frameworks, and models. Singapore Management Review, 26(1), 45-61.

Asmussen, C.G., Pedersen, T., \& Dhanaraj, C. (2009). Host-country environment and subsidiary competence: Extending the diamond network model. Journal of International Business Studies, 40(1), 42-57. https://doi.org/10.1057/palgrave.jibs. 8400420

Bakan, I., \& Doğan, İ.F. (2012). Competitiveness of the industries based on the Porter's diamond model: An empirical study. International Journal of Research and Reviens in Applied Sciences, 11(3), 441-455.

Barnard, H., \& Tuomi, K. (2008). How demand sophistication (De-) limits economic upgrading: Comparing the film industries of South Africa and Nigeria (Nollywood). Industry and Innovation, 15(6), 647-668. https://doi.org/10.1080/13662710802568986

Bhattacharjee, S., \& Chakrabarti, D. (2015). Investigating India’s competitive edge in the IT-ITeS sector. IIMB Management Review, 27(1),19-34. https://doi.org/10.1016/j.iimb.2015.01.003

Brettel, M., Friederichsen, N., Keller, M., \& Rosenberg, M. (2014). How virtualization, decentralization and network building change the manufacturing landscape: An industry 4.0 perspective. International journal of mechanical, industrial science and engineering, 8(1), 37-44.

Bridwell, L., \& Kuo, C. (2005). An analysis of the computer industry in China and Taiwan using Michael Porter's determinants of national competitive advantage. Competitiveness Review, 15(2), 116-120. https://doi.org/10.1108/cr.2005.15.2.116

Brosnan, S., Doyle, E., \& O'Connor, S. (2016). From Marshall's Triad to Porter's Diamond: added value? Competitiveness Review, 26(5), 500-516. https://doi.org/10.1108/CR-05-2015-0037

Castelo-Branco, I., Cruz-Jesus, F., \& Oliveira, T. (2019). Assessing Industry 4.0 readiness in manufacturing: Evidence for the European Union. Computers in Industry, 107, 22-32. https://doi.org/10.1016/j.compind.2019.01.007

Chung, T.W. (2016). A Study on Logistics Cluster Competitiveness among Asia Main Countries using the Porter's Diamond Model. The Asian Journal of Shipping and Logistics, 32(4), 257-264. https://doi.org/10.1016/j.ajsl.2016.12.010

Drath, R., \& Horch, A. (2014). Industrie 4.0: Hit or hype?[industry forum]. IEEE industrial electronics magazine, 8(2), 56-58. https://doi.org/10.1109/MIE.2014.2312079

Esen, S., \& Uyar, H. (2012). Examining the Competitive Structure of Turkish Tourism Industry in Comparison with Diamond Model. Procedia - Social and Behavioral Sciences, 62, 620-627. https://doi.org/10.1016/j.sbspro.2012.09.104

Fang, K., Zhou, Y., Wang, S., Ye, R., \& Guo, S. (2018). Assessing national renewable energy competitiveness of the G20: A revised Porter's Diamond Model. Renewable and Sustainable Energy Reviews, 93,719-731. https://doi.org/10.1016/j.rser.2018.05.011

Ghobakhloo, M. (2018). The future of manufacturing industry: A strategic roadmap toward Industry 4.0. Journal of Manufacturing Technology Management, 29(6), 910-936. https://doi.org/10.1108/JMTM-02-2018-0057

Guan, Z., Xu, Y., Jiang, H., \& Jiang, G. (2018). International competitiveness of Chinese textile and clothing industry - a diamond model approach. Journal of Chinese Economic and Foreign Trade Studies. https://doi.org/10.1108/JCEFTS-01-2018-0003

Heeks, R. (2006). Using competitive advantage theory to analyze IT sectors in developing countries: a software industry case analysis. Information Technologies \& International Development, 3(3), 5.

https://doi.org/10.1162/itid.2007.3.3.5 
Hermann, M., Pentek, T., \& Otto, B. (2016). Design principles for industrie 4.0 scenarios. In 2016 49th Hawaii international conference on system sciences (HICSS), 3928-3937. IEEE. https:// doi.org/10.1109/HICSS.2016.488

Hofmann, E., \& Rüsch, M. (2017). Industry 4.0 and the current status as well as future prospects on logistics. Computers in Industry, 89,23-34. https://doi.org/10.1016/j.compind.2017.04.002

Jin, B., \& Moon, H. (2006). The diamond approach to the competitiveness of Korea's apparel industry. Journal of Fashion Marketing and Management: An International Journal, 10(2), 195-208. https://doi.org/10.1108/13612020610667504

Kagermann, H. (2015). Change through digitization - Value creation in the age of Industry 4.0. In Management of permanent change, 23-45. Springer Gabler, Wiesbaden. https://doi.org/10.1007/978-3-658-05014-6_2

Kharub, M., \& Sharma, R. (2017). Comparative analyses of competitive advantage using Porter diamond model (the case of MSMEs in Himachal Pradesh). Competitiveness Review, 27(2), 132-160. https://doi.org/10.1108/CR-02-20160007

Kolberg, D., \& Zühlke, D. (2015). Lean automation enabled by industry 4.0 technologies. IFAC-PapersOnLine, 48(3),1870-1875. https://doi.org/10.1016/j.ifacol.2015.06.359

Lasi, H., Fettke, P., Kemper, H.G., Feld, T., \& Hoffmann, M. (2014). Industry 4.0. Business \& information systems engineering, 6(4),239-242. https://doi.org/10.1007/s12599-014-0334-4

Lee, J., Bagheri, B., \& Kao, H.A. (2015). A cyber-physical systems architecture for industry 4.0-based manufacturing systems. Manufacturing letters, 3,18-23. https://doi.org/10.1016/j.mfglet.2014.12.001

Lin, C.-H. (2011). Industry-specific competitiveness of a nation and its consequence on overseas marketing performance: Measurement construction and empirical study that follows porter's diamond model. Journal of Information and Optimization Sciences, 32(3), 605-620. https://doi.org/10.1080/02522667.2011.10700075

Lu, Y. (2017). Industry 4.0: A survey on technologies, applications and open research issues. Journal of Industrial Information Integration, 6,1-10. https://doi.org/10.1016/j.jii.2017.04.005

MAKFED (2018). Makine ve Imalat Sektörü:Türkiye ve Dünya Değerlendirme Raporu 2018. MAKFED Reports. Available at: http://www.makfed.org/images/s/DegerlendirmeRaporu.pdf

Mittal, S., Khan, M.A., Romero, D., \& Wuest, T. (2018). A critical review of smart manufacturing \& Industry 4.0 maturity models: Implications for small and medium-sized enterprises (SMEs). Journal of manufacturing systems, 49,194-214. https://doi.org/10.1016/j.jmsy.2018.10.005

Moon, H.C., Rugman, A.M., \& Verbeke, A. (1998). A generalized double diamond approach to the global competitiveness of Korea and Singapore. International business review, 7(2), 135-150. https://doi.org/10.1016/S09695931(98)00002-X

Müller, J.M., Buliga, O., \& Voigt, K.I. (2018). Fortune favors the prepared: How SMEs approach business model innovations in Industry 4.0. Technological Forecasting and Social Change, 132, 2-17.

https://doi.org/10.1016/j.techfore.2017.12.019

Nanda, T., \& Singh, T.P. (2009). An assessment of the technology innovation initiatives in the Indian small manufacturing industry. International Journal of Technology, Policy and Management, 9(2), 173-207.

https://doi.org/10.1504/IJTPM.2009.025292

Petrakis, P.E., Kostis, PC., \& Valsamis, D.G. (2015). Innovation and competitiveness: Culture as a long-term strategic instrument during the European Great Recession. Journal of Business Research, 68(7), 1436-1438. https://doi.org/10.1016/j.jbusres.2015.01.029

Porter, M.E. (1990). The competitive advantage of nations. New York: The Free Press. A Division of Macmillan Incorporation. https://doi.org/10.1007/978-1-349-11336-1_3

Porter, M. (1998). The competitive advantage of nations. New York: Free Press. https://doi.org/10.1007/978-1-349-148653_3 
Porter, M.E., \& Heppelmann, J.E., (2014). How smart, connected products are transforming competition. Harvard Business Review, 92 (11), 64-88.

Riasi, A. (2015). Competitive advantages of shadow banking industry: An analysis using Porter diamond model. Business Management and Strategy, 6(2), 15-27. https://doi.org/10.5296/bms.v6i2.8334

Rojaka, J. (2015). Baltic states competitiveness: before and after the global crisis. Applied Economics: Systematic Research, 3(1), 27-46.

Sanders, A., Elangeswaran, C., \& Wulfsberg, J.P. (2016). Industry 4.0 implies lean manufacturing: Research activities in industry 4.0 function as enablers for lean manufacturing. Journal of Industrial Engineering and Management (JIEM), 9(3), 811-833. https://doi.org/10.3926/jiem.1940

Szalavetz, A. (2018). Industry 4.0 and capability development in manufacturing subsidiaries. Technological Forecasting and Social Change. https://doi.org/10.1016/j.techfore.2018.06.027

Wang, S., Wan, J., Li, D., \& Zhang, C. (2016). Implementing smart factory of industrie 4.0: an outlook. International Journal of Distributed Sensor Networks, 12(1), 3159805. https://doi.org/10.1155/2016/3159805

Wilkesmann, M., \& Wilkesmann, U. (2018). Industry 4.0-organizing routines or innovations?. VINE Journal of Information and Knowledge Management Systems, 48(2), 238-254. https://doi.org/10.1108/VJIKMS-04-2017-0019

WEF (2018). Global Competitiveness Report 2017-2018. Switzerland: Klaus Schwab (ed.).

Journal of Industrial Engineering and Management, 2020 (www.jiem.org)

\section{(ब) (1) (}

Article's contents are provided on an Attribution-Non Commercial 4.0 Creative commons International License. Readers are allowed to copy, distribute and communicate article's contents, provided the author's and Journal of Industrial Engineering and Management's names are included. It must not be used for commercial purposes. To see the complete license contents, please visit https://creativecommons.org/licenses/by-nc/4.0/. 